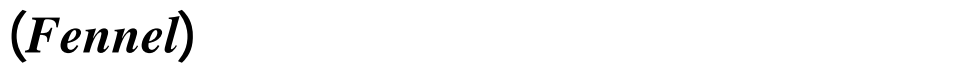 الني ينموفيشمل الهرق
}

\author{
مقداد توفيق ليوب \\ كلية العلوم لكوفيون \\ قصم الكيمياء \\ ج - ملمعة الم - -وصل
}

\author{
طلمت رالجح الروضلف \\ كلية الصيدلة \\ وحة النبانتا الطبية \\ ج ـ المعة الم - -وصل
}

(تاريخ الاستلام 2001/8/20 ، تاريخ القبول 2001/12/2)

الملغص

مُ درلسة مكونات المستخلص الكحولي والمائي لبذور نببت المثمر بلستخدلم ققنية كروماتوغرافية

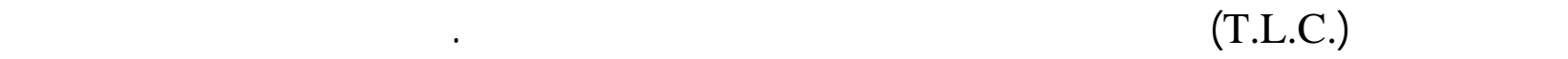

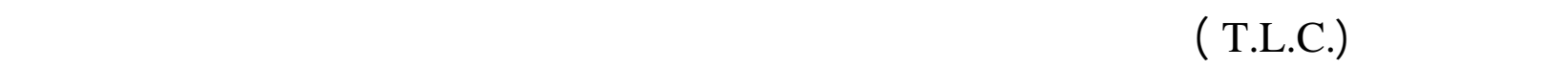

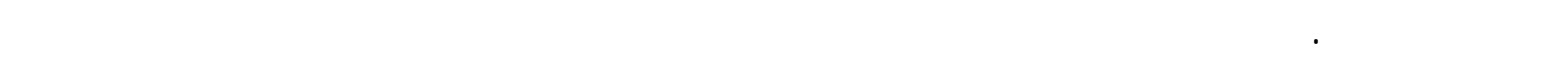

الكيميائية اللونية المتعلقة بها.

\section{Study on Flavonoids from (Fennel) Seeds \\ which Grows in the North of Iraq}

Talat R. Al-Ramadhany

Medicinal Plants Unit

College of Pharmacy

MosulUniversity

\section{Mikdad T. Ayoub}

Department of Chemistry

College of Science

MosulUniversity

\section{ABSTRACT}

A methanol and aqueous extracts of fennel seeds showed the presence of new flavonoides with its glycosides. The analysis of flavonoides glycoside and its aglycone was made by three chromatographic techniques: thin layer chromatography (T.L.C), twoensional T.L.C and column chromatography. and with comparing the relative retention times of the resolved peaks with those of authentic samples analyzed under the same experimental conditions. 


\section{المقمة}

تعد الفلافينويدات من المركبك الأوكسجينية الحلقية غير المتجلنسة المهمة والأسلسية في النباة لت،

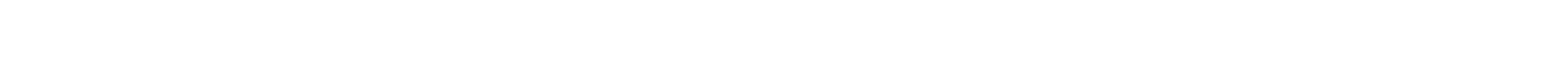

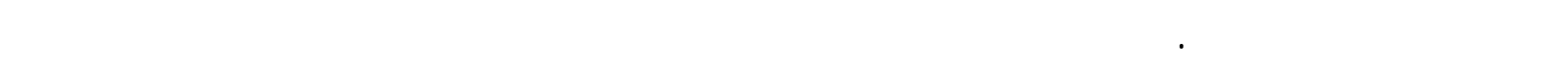

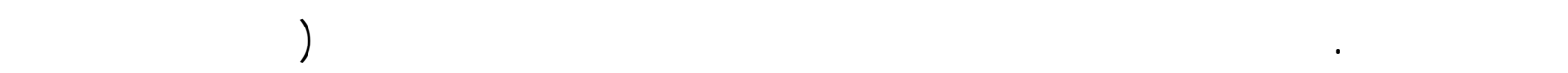

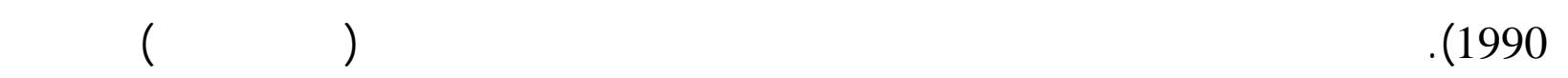

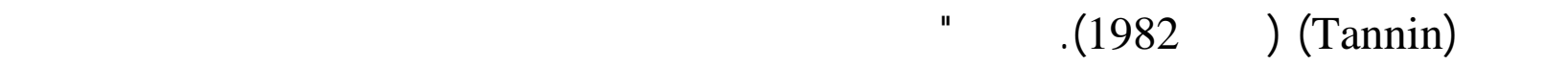

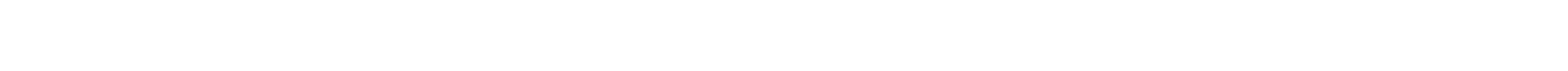

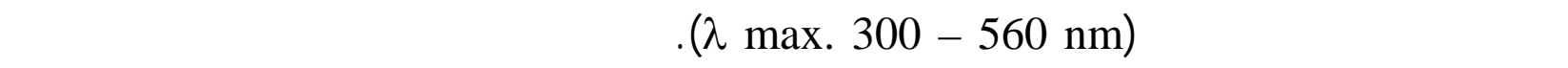

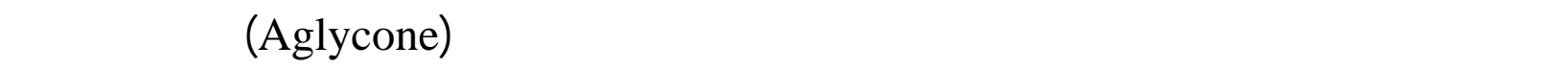
المفصولة والمشتورة (Harborne, 1973 حيث يوجد عدد كبير من الكلايكوسيدات لمركب كلايك ـوني

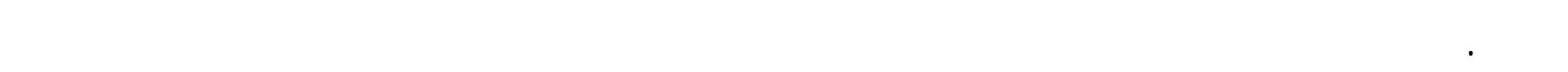
أو الثنائي البعد (One Dimension) المشورة (Harborne, 1967 ; Mabry et al., 1970).

\section{النتائج والمنالثشة}

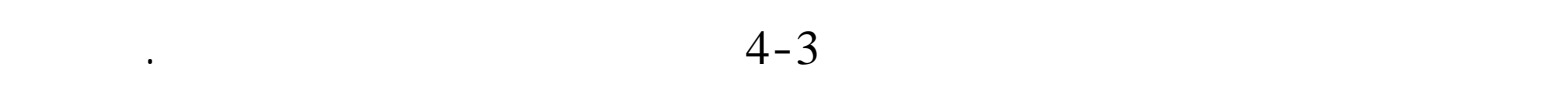
الميثانول بلستخدلم جهاز النظير تُمت الضغط المخلخل ليطي مادة زيتية بنية اللون ثخينة الق ـوله وذات

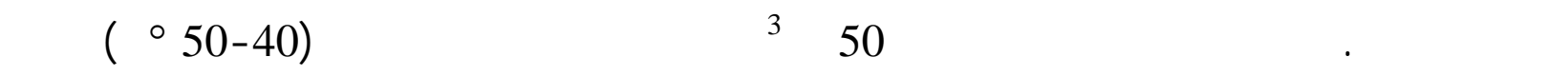

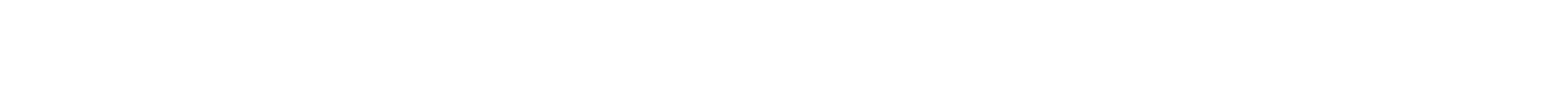

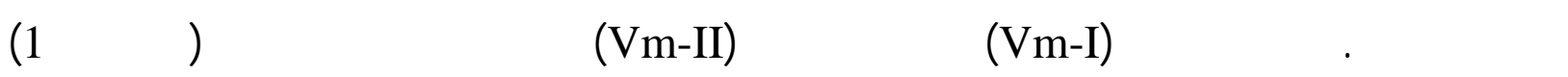

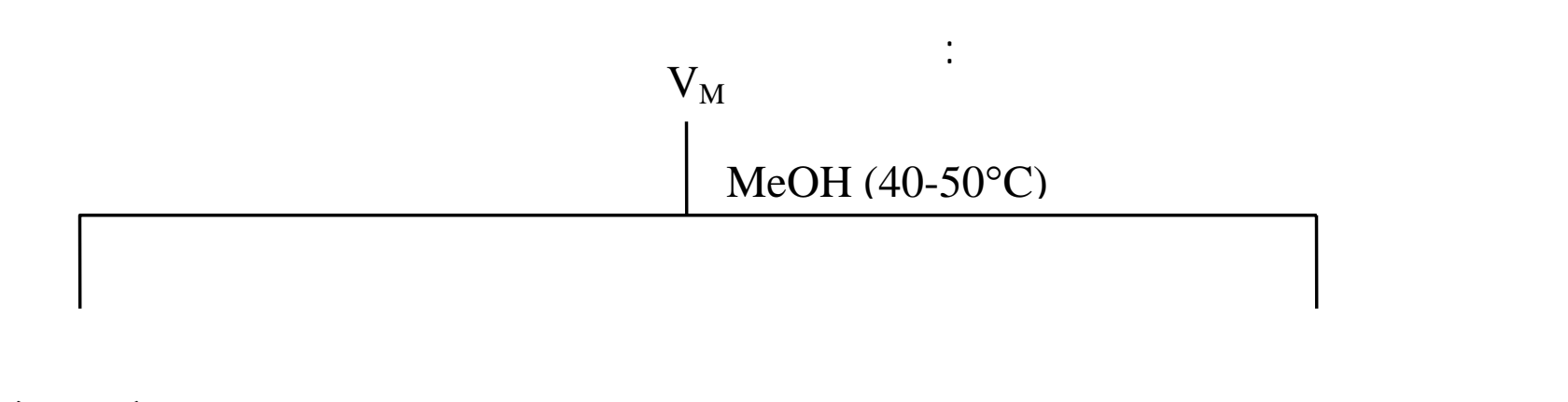

(Vm-II)

(Vm-I)

مخطط 1: يبين فصل مكونات المستخلص الكحولي 
1. الرلسب (Vm-I) : تمل الكلايكوسيدات لحد المركبلت الأسلسية الموجودة في النبات والتي تك ـون

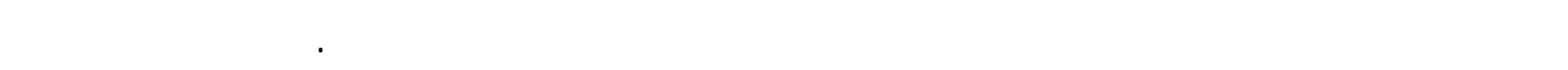

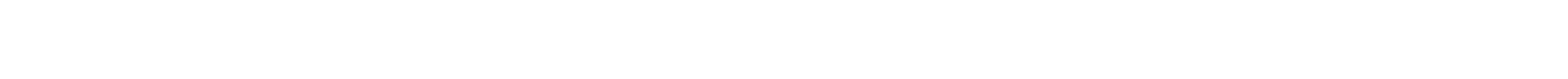
إلى الكحول المقابل (الكلايكون) وللسكر.

$$
\begin{aligned}
\text { Ar-O-glycoside }+\mathrm{H}^{+} & \rightarrow \text { ArOH }{ }^{*}+\text { Sugar } \\
& \text { (aglycone) }
\end{aligned}
$$

ArOH (* عند تحليل الرلسب (Vm-I) بلستخده 2M حلمض الهيدروكلوريك ولستخلاص الكلايكون لت

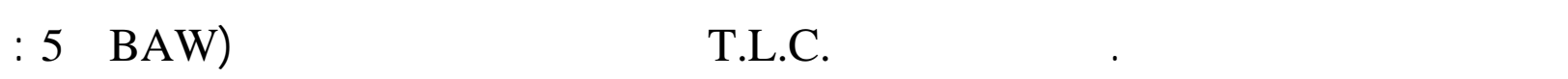

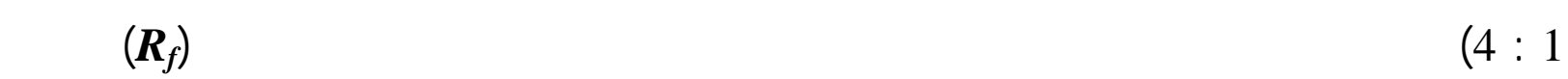

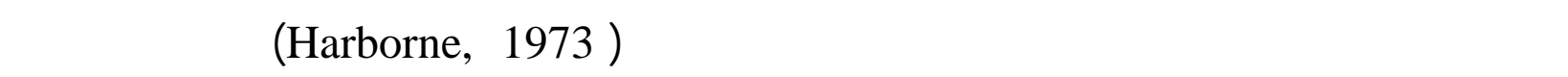

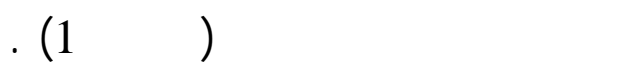<smiles>[R]c1cc(-c2oc3cc(O)cc(O)c3c(=O)c2O)cc([R])c1O</smiles>

(1), $\mathbf{R}=\mathbf{O H}$

(2), $\mathbf{R}=\mathbf{H}$<smiles>[R20]Oc1cc(-c2oc3cc(O)cc([R20])c3c(=O)c2O)ccc1O</smiles>

(3), $\mathbf{R}_{1}=\mathbf{R}_{2}=\mathbf{H}$

(4), $R_{1}=M e, R_{2}=H$ 


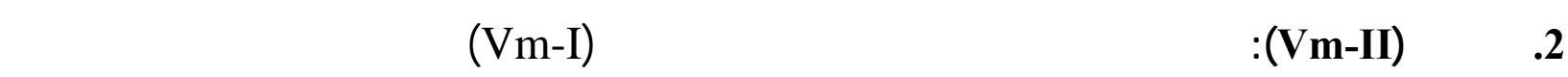

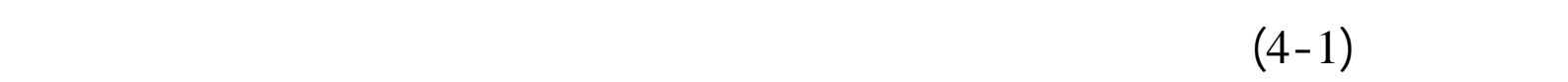

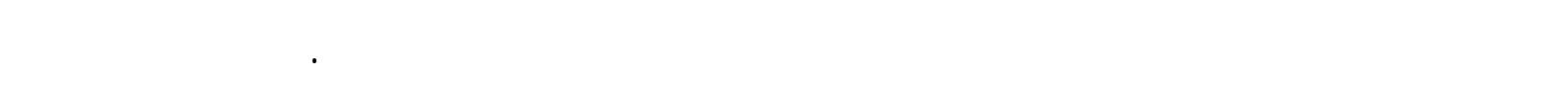

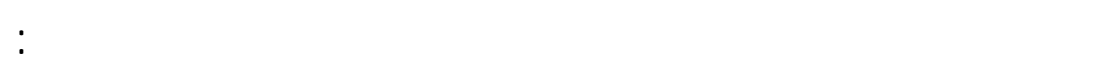

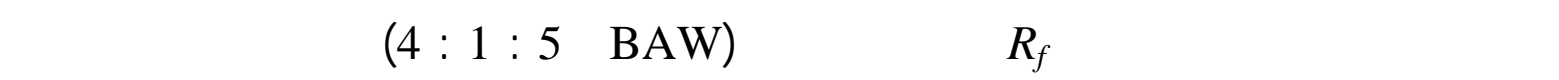

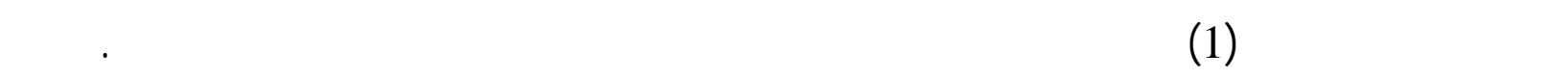

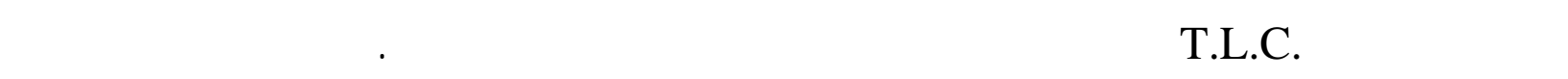

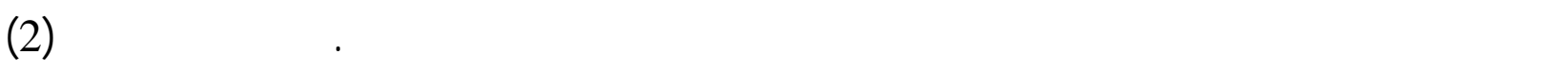

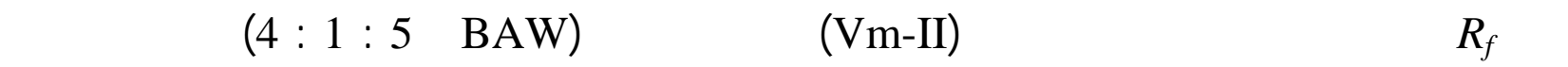

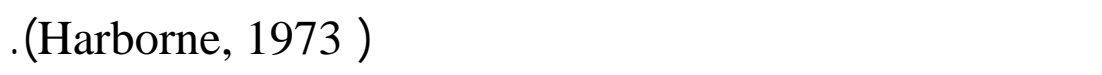

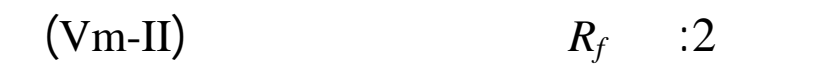

\begin{tabular}{|c|c|c|}
\hline \multicolumn{2}{|c|}{$R_{f}(X 00)$} & \multirow{2}{*}{ المركب } \\
\hline المششورة & المقلسة & \\
\hline 24 & 25 & ميسستن - 5 - مثيل ايثر (5) \\
\hline 32 & 32.5 & كووستين - 7 - كلايكوسيد (6) \\
\hline 43 & 43 & ميرستين (1) \\
\hline 48 & 48 & كوبستين - -4 - كلايكوسيد (7) \\
\hline 64 & 62 & كوبستين (2) \\
\hline 74 & 73 & إيزوهلمنتين (3) \\
\hline 83 & 85 & كلففيرول (4) \\
\hline
\end{tabular}<smiles>COc1cc(O)cc2oc(-c3cc(O)c(O)c(O)c3)c(O)c(=O)c12</smiles>

(5)<smiles>[R20]Oc1cc(O)c2c(=O)c(O)c(-c3ccc(O[R2])c(O)c3)oc2c1</smiles>

(6), $R_{1}=H, R_{2}=$ gl.

(7), $\mathbf{R}_{1}=$ gl., $\mathbf{R}_{\mathbf{2}}=\mathbf{H}$ 


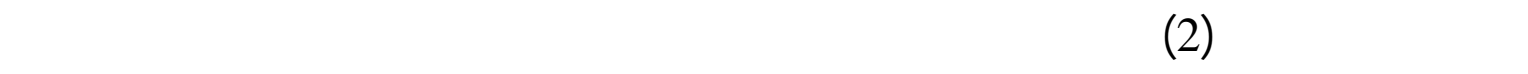
في جزئي الرلسب (Vm-I) والرلشح (2) (Vm-II) بعد إجراء عملية التحل الحلمضي ، حيث لوحظظون فيكور

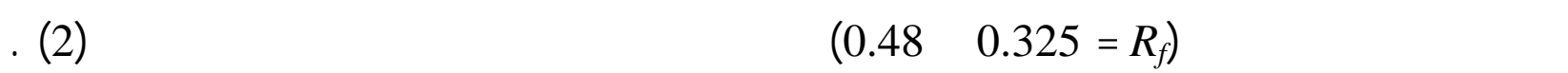

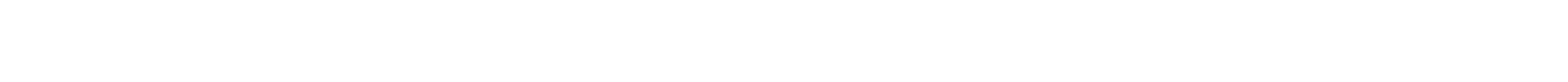
بنوعيها الحر الكلايكوسيدي والتي هي الميرستين (1)، الكوبستين(2)، ليزوه المنتين (3) والك المفيرول

لما الاختبار الثاني للرلشح (Vm-II) فقدشهل درلسة قيمسرع الانسيلب (R) بلستخدلم تقني ة

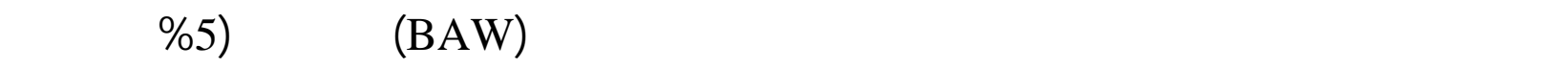

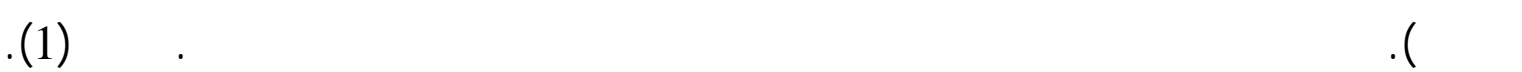

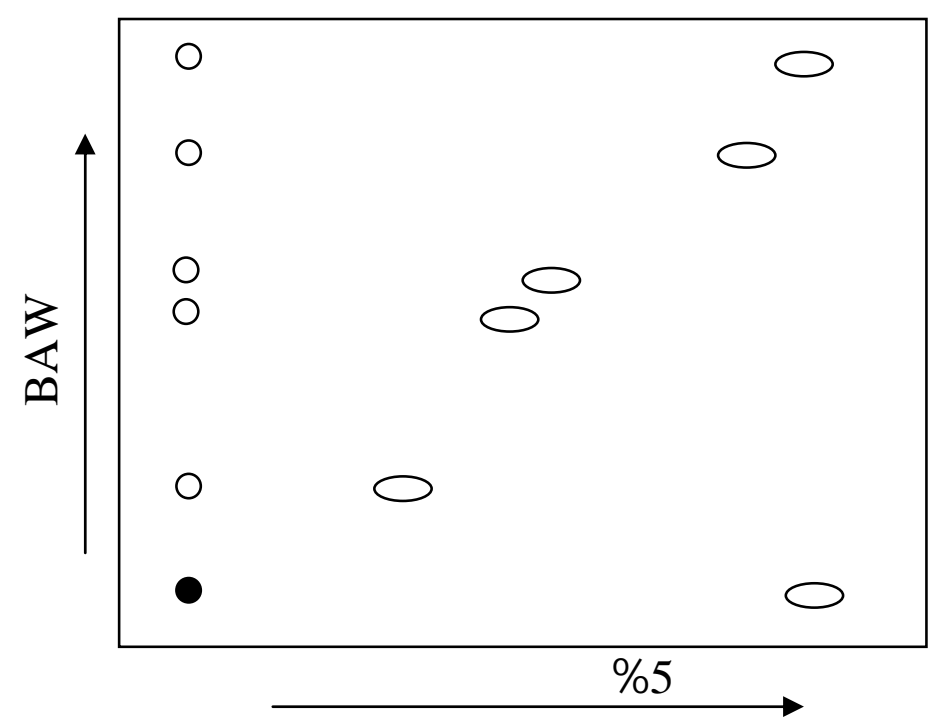

اللشكل 1: يبنظهور القع بعد تعريض الصفيحة لبخار اليود بلستخدلم تقنية كروماتوغرافيا الطقة الرقيقة

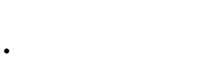

وعلى الرغم من وجود قناعة كلملة بانتمائها إلى كلايكوسيدات الكورستين ومشقاته الفلافينويدي ة

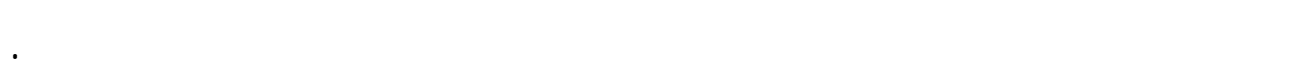

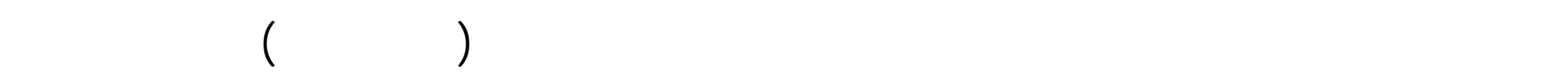

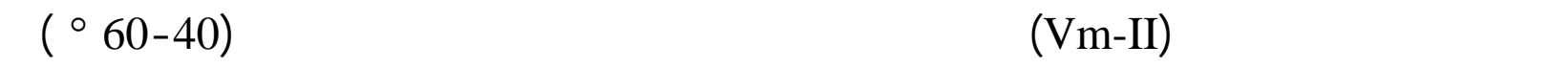

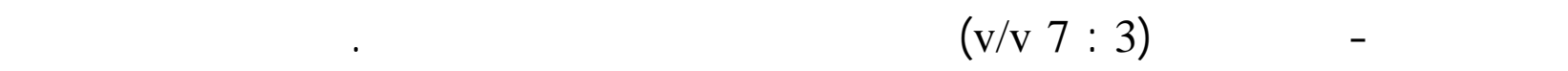

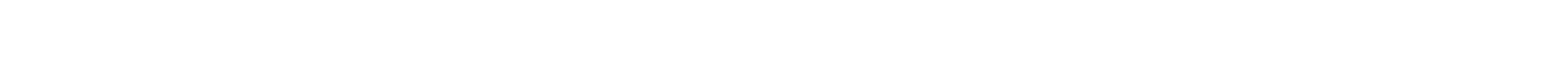

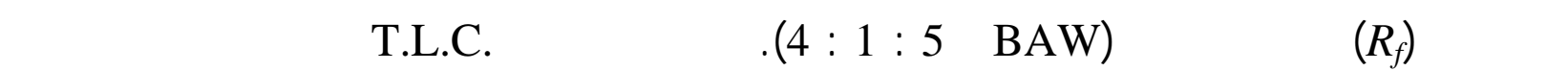

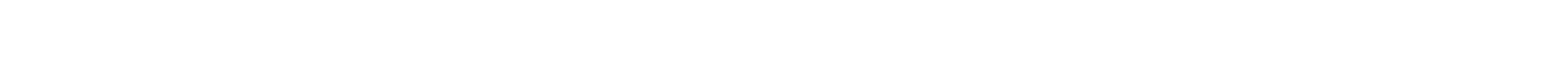




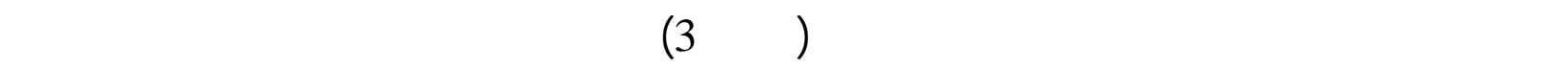
المركبلت وبلستخدلم الظروف فنها (Harborne, 1973) وجد أن بعضأمنها مشابه لتل لك الت مي ت م تشخيصها آنفاً. جدول 3: قيم

\begin{tabular}{|c|c|c|c|c|c|}
\hline $\begin{array}{c}R_{f} \\
(\times 100)\end{array}$ & المركب (مستخلص & $\begin{array}{c}R_{f} \\
(\times 100)\end{array}$ & المركب (مستخلص الكلوروفورم) & $\begin{array}{c}R_{f} \\
(\mathbf{X 1 0 0})\end{array}$ & الالايثر البترولي) (مستخلص) \\
\hline 76 & ايزوهلمنتين (3) & 25 & ميستين -5 -مثل & 51 & كوبستين -5 - مثيل \\
\hline \multirow[t]{3}{*}{88} & كلففيرول (4) & 65 & كورستين (2) & 62 & كوبستين (2) \\
\hline & & 72 & ايزوهلمنتين (3) & 78 & إيزوهلمنتين (3) \\
\hline & & 88 & كلمفيرول (4) & & \\
\hline
\end{tabular}<smiles>COc1cc(O)cc2oc(-c3ccc(O)c(O)c3)c(O)c(=O)c12</smiles>

(8)

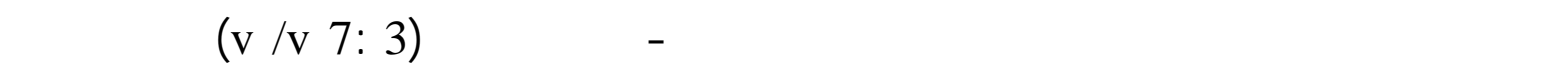

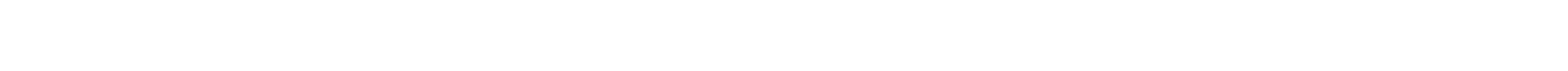
(G.C.) النتيجة .

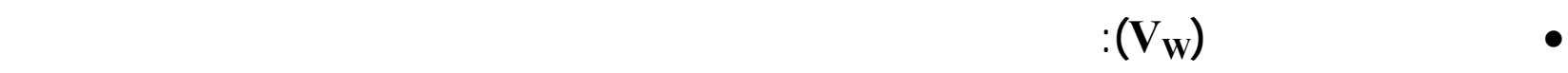

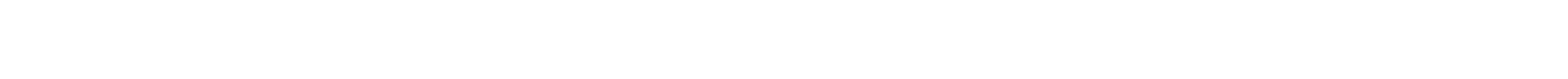
على كمية لكبرمن المركبك التطبية مل الكلايكوسيدات الفلافينويية فضلاً عن كلايكوسيدات لأخ ـرى.

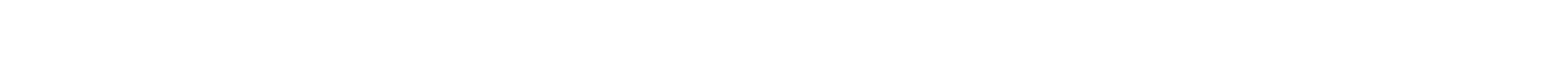
الميثانول، مُ تششح وتركز الطقة المائية بلستخدلم جهاز النظير تهمت الضغط المخلخل وبلستخدلم حملم

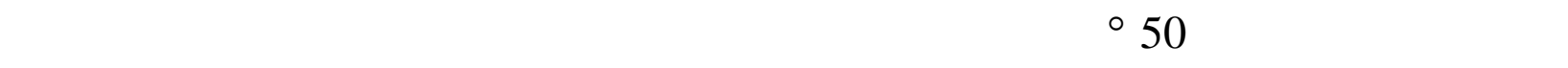

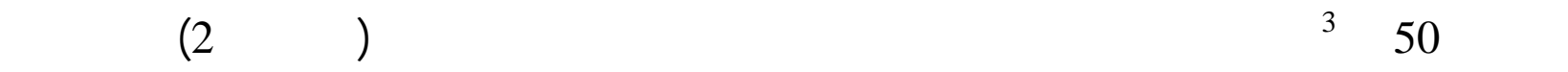
الرلمب (V) تحت الضغط المخلخل لدرلسة مكوناتهما الكيميائية. 


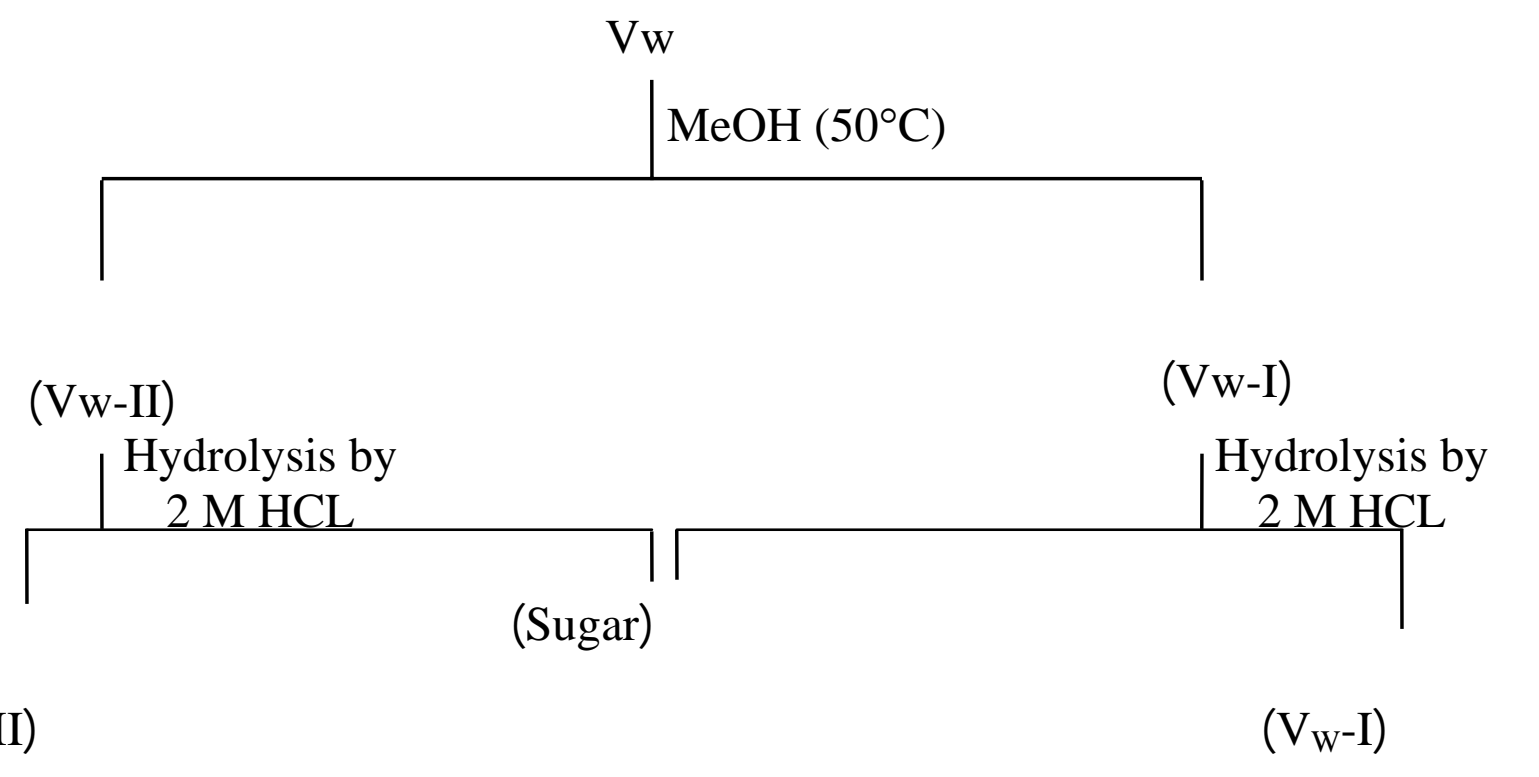

مخطط 2: يبين فصل مكونات المستخلص المائي

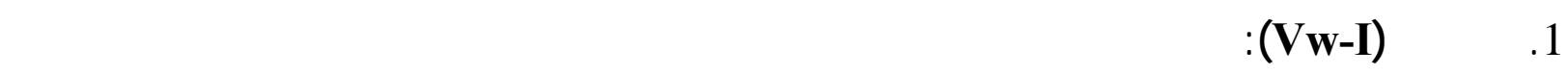

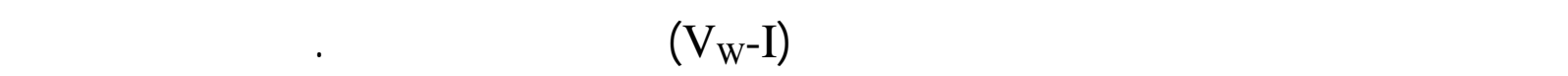

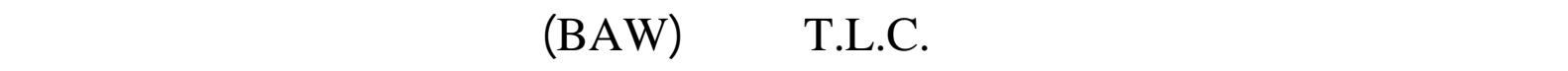
وبلستخدلم كلثف فولن وبخار الأمونيا .وقد أوضحت الدرلسةظهور ثلاتلاث ققع (

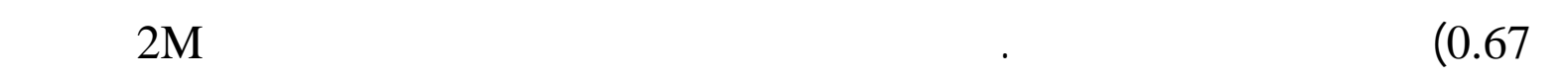

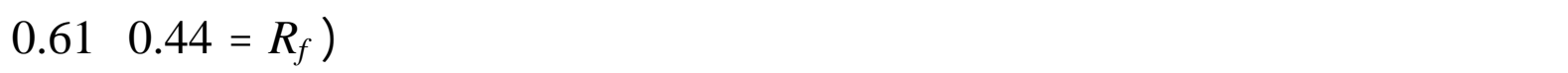

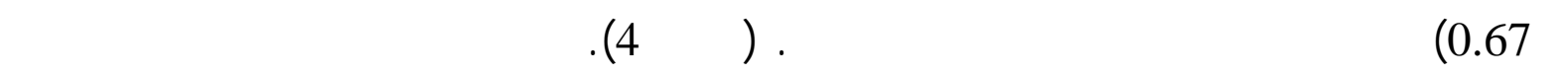

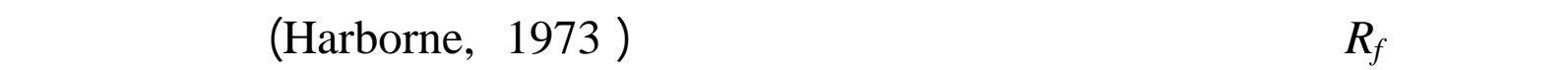

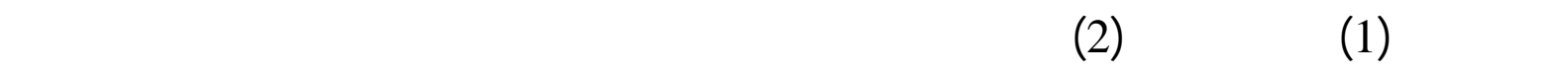
كلايكوسيدات.

جدول 4 : قيم $R_{f}$ لبعض مركببت الرلمب (V)-I) المشخصة قبل وبعد التحل الحلمضي

\begin{tabular}{|c|c|c|c|c|c|}
\hline \multicolumn{2}{|c|}{$R_{f}(\mathbf{X 1 0 0 )}$} & \multirow{2}{*}{ المركب ( بهد التطل الحاهضي) } & \multicolumn{2}{|c|}{$R_{f}(\times 100)$} & \multirow{2}{*}{ المركب (قل النطل الحامضي) } \\
\hline المنشورة & المقلسة & & المشورة & المقلسة & \\
\hline 43 & 44 & ميرستين (1) & 48 & 49 & كوبستن --4 - كلايكوسيد (7) \\
\hline 64 & 61 & كوبستين (2) & 58 & 59 & كووستين - 3 - كلايكوسيد (9) \\
\hline 64 & 67 & كوبستين -3 - مثل ايثر(11) & 65 & 67 & كوبستين - 3 - زايلوسيد (10) \\
\hline
\end{tabular}




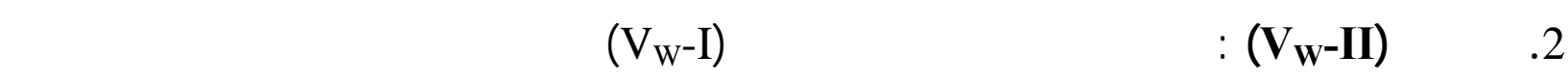

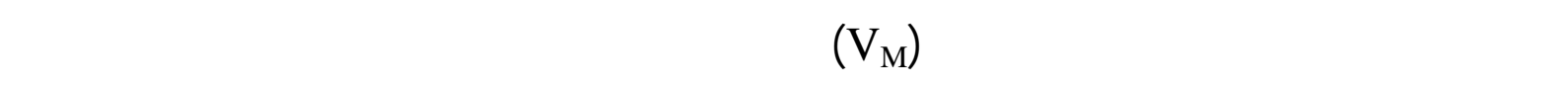
T.L.C. هذه الدرلسة فقد مم الكثف عن الفلافينويدات الموجوة في الرلشح (V)

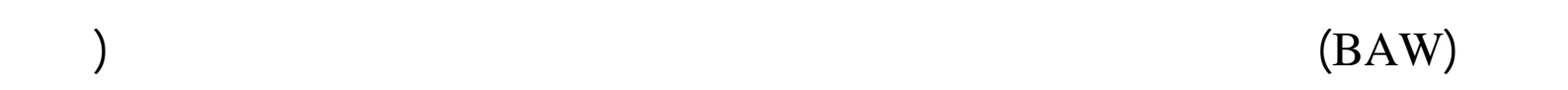

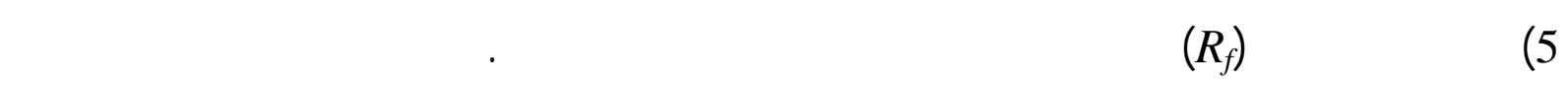

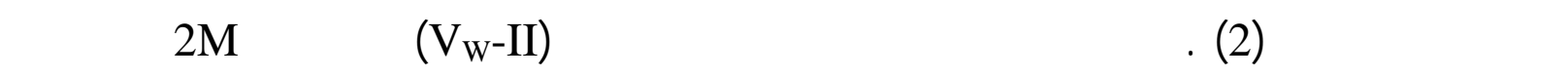

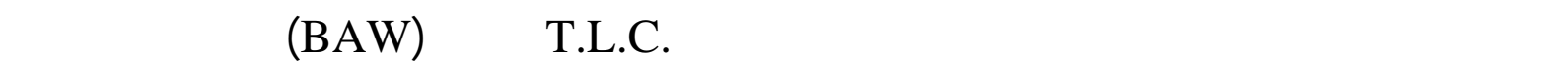

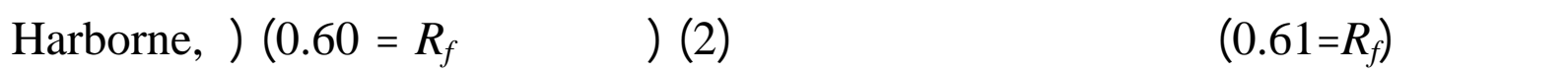

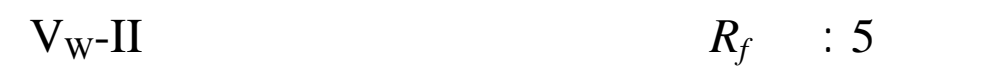

\begin{tabular}{|c|c|c|}
\hline \multicolumn{2}{|c|}{$R_{f}(\times 100)$} & \multirow{2}{*}{ المركب } \\
\hline المشورة & المقلسة & \\
\hline 40 & 40 & كووستين - 3 - كلوكورنيد(12) \\
\hline 58 & 54 & كوبستين - 3 -كلايكوسيد (9) \\
\hline 70 & 70 & كورستين -3 -أرابينوسيد (13) \\
\hline
\end{tabular}<smiles>[R]c1c(-c2ccc(O)c(O)c2)oc2cc(O)cc(O)c2c1=O</smiles>

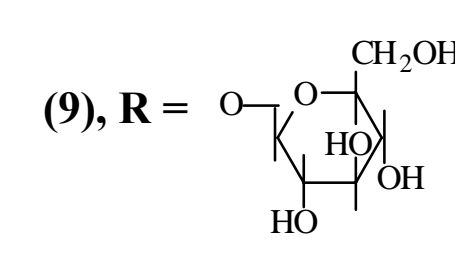

(10), $\mathbf{R}={ }^{\mathrm{O}}$

(11), $R=$ OMe
(12), $\mathrm{R}=$

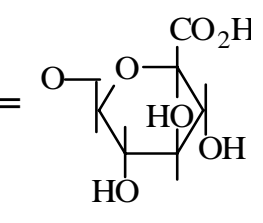

(13), $\mathbf{R}=$ OOH 


\section{المواد ولرلق العل}

1. المادة النباتية: لخذت بذور الشمر من الأسواق المحلية والتي جمعت حديثًا من مطقة الجزيرة

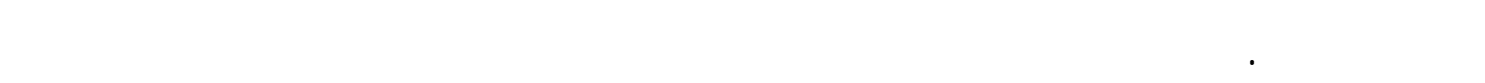

بلستخدل جهاز الاستخلاص المستمر (Soxhlet) .

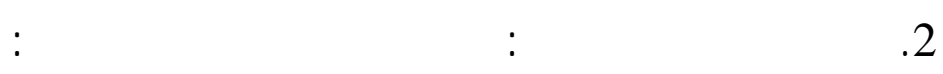

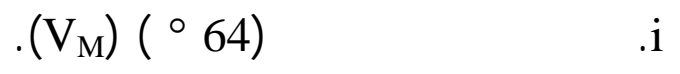

$$
\begin{aligned}
& \text { ii }
\end{aligned}
$$

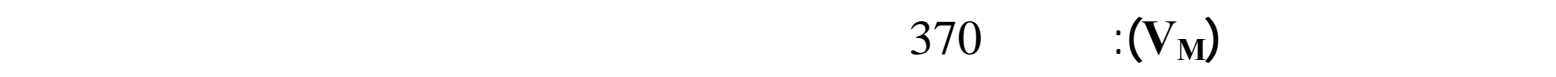

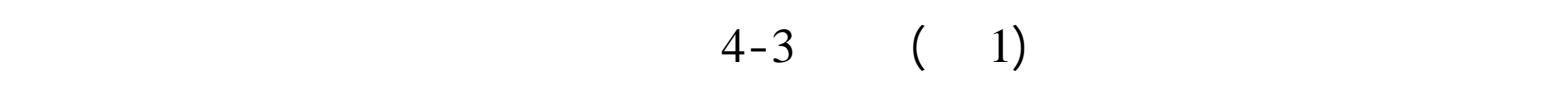

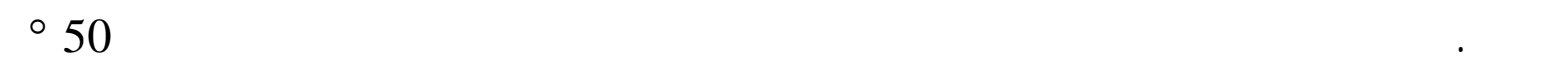

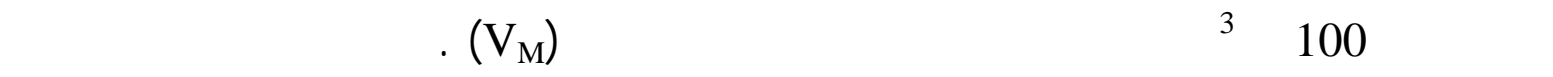

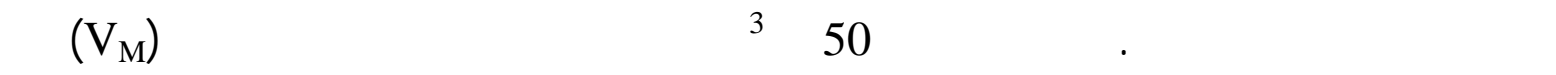

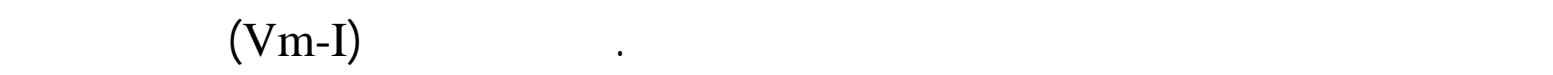

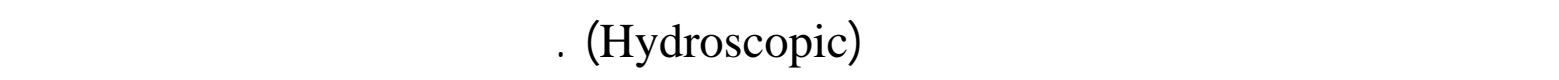
التطير تهت الضغط المخلغل ليطي مادة زيتية بنية غلمقة اللون (Vm-II) .

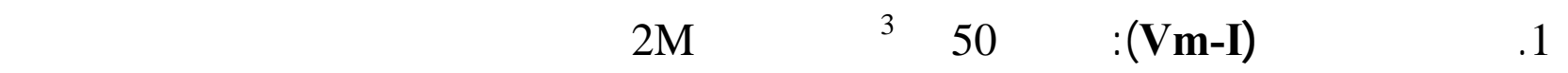
العلكي(V

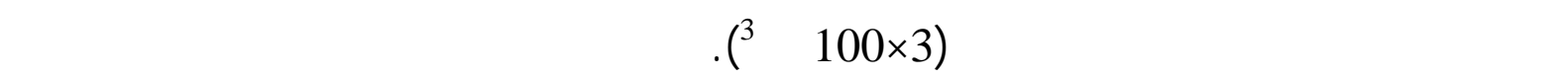
المغنيسيوم اللمائية (المون

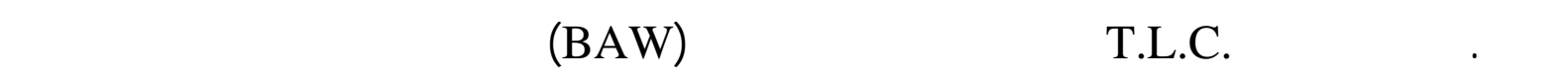

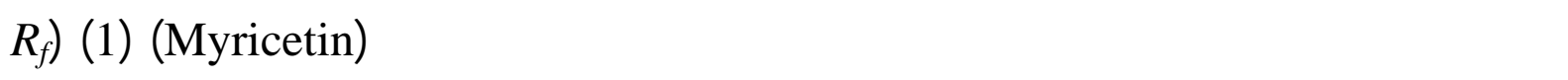

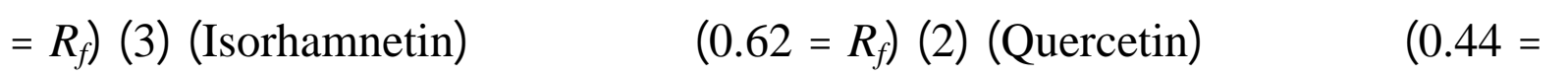

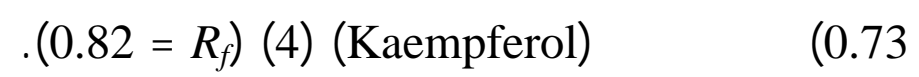
2. تحليل الرلشح (Vm - II) : لستخدم الرالشح (Vm-II) في ثلاثة لختبارات، يـ ششمل الاختب ار الأول

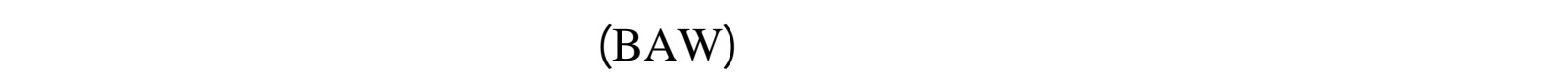

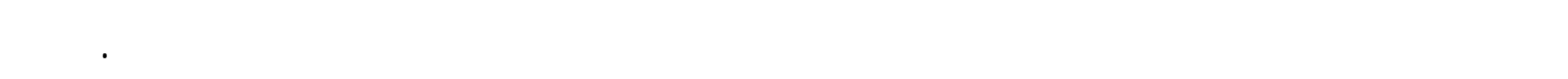
كانت قيم لنسيابها كما يأتي:

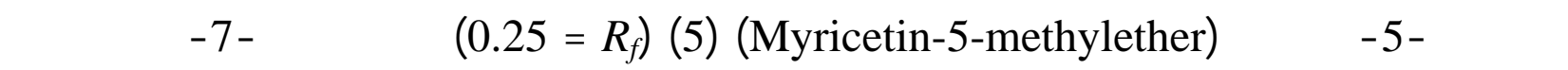

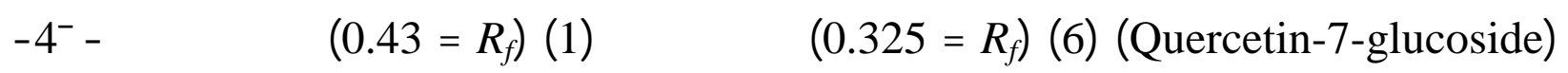




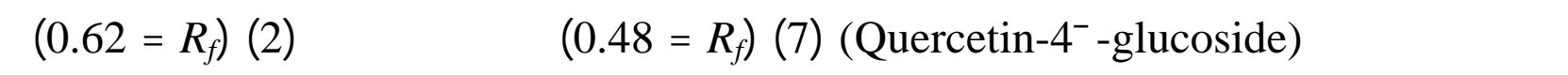

$$
\text { ايزوهلمنتين (3) (3) }
$$

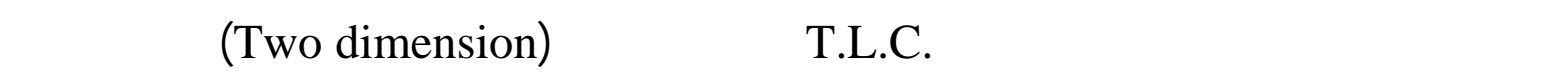

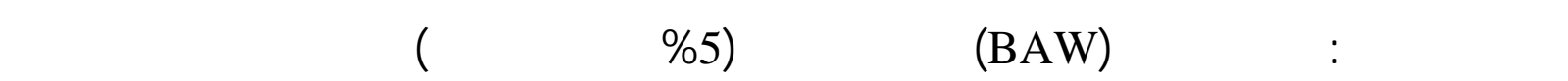

لبخار اليودظهرتست فقع.

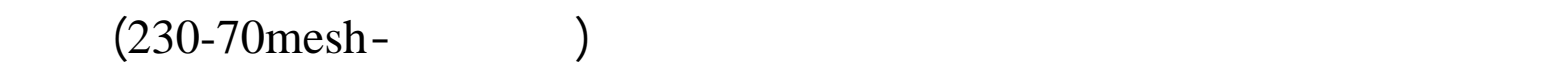

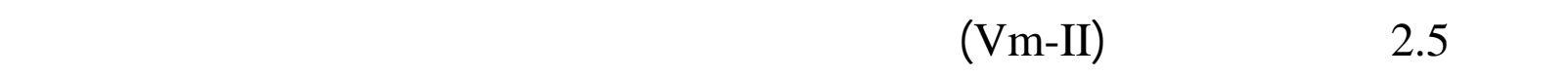

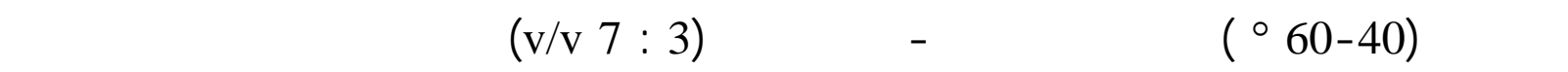

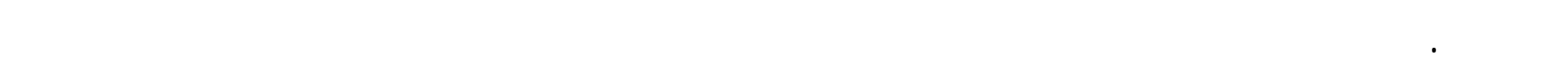

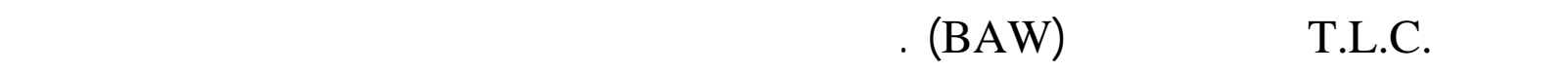

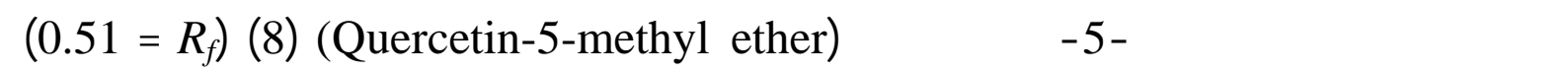
الكوبستن (2) (2=R أوضحظهور اريع ققع تعود إلى الميرستين - 5 - مثيل اليثر (5) (0. 0.65 = إيزوهلمنتين (3) (3) =

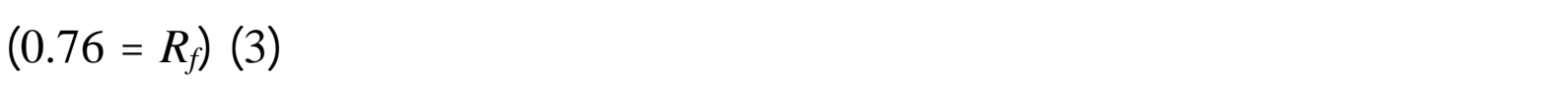

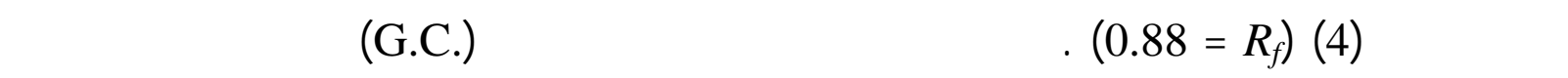

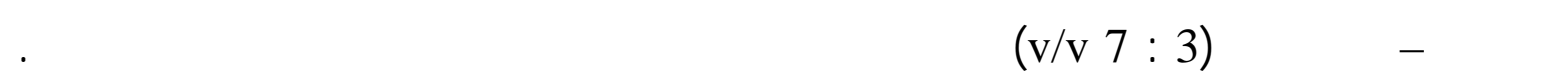

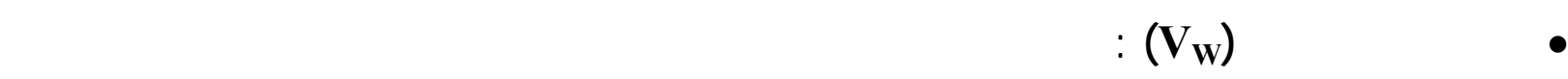

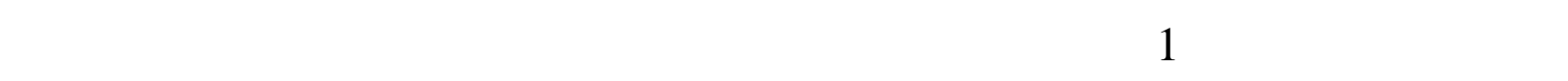

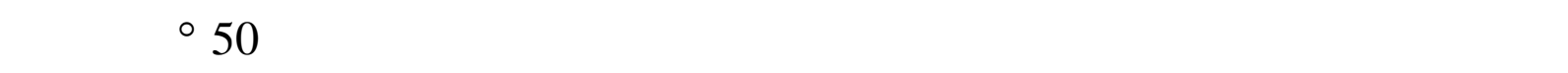

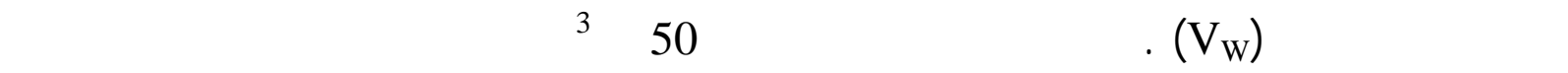

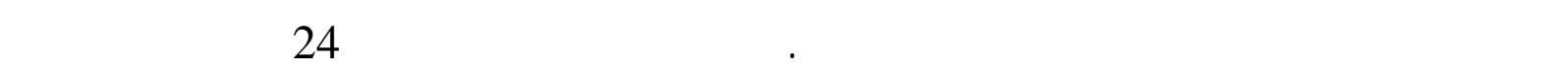
الرلمب المتميء (VW-

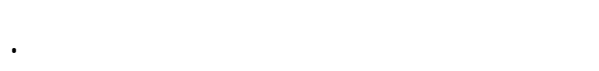

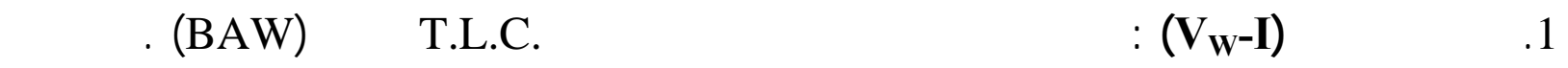
الاختبار الأول قبل تحل الرلمب (V)

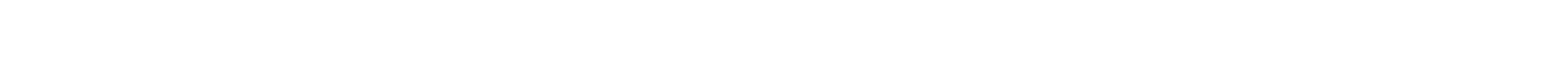

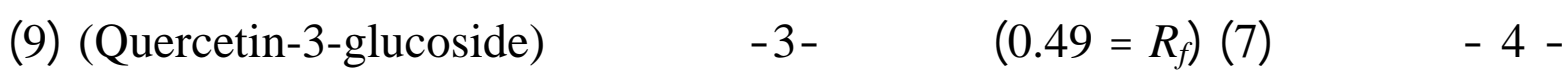

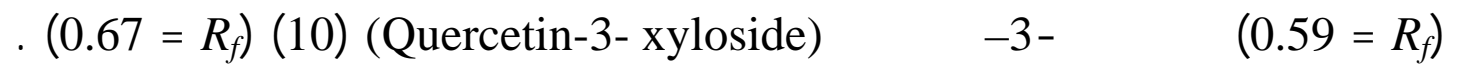




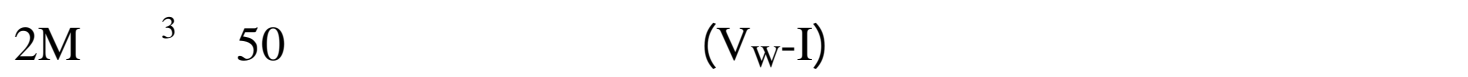

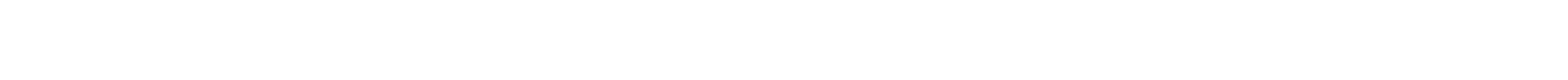

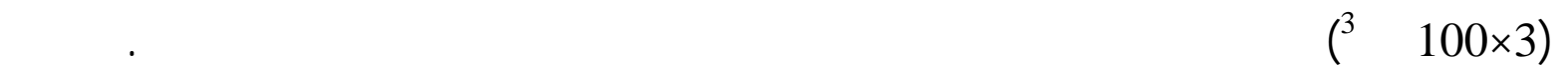

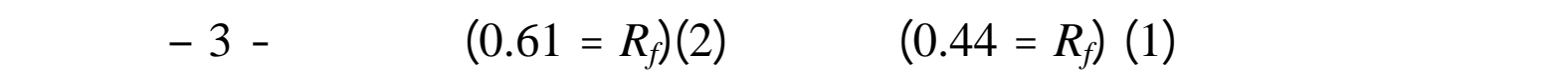
. $\left(0.67=R_{f}\right)(11)$ (Quercetin-3-methyl ether)

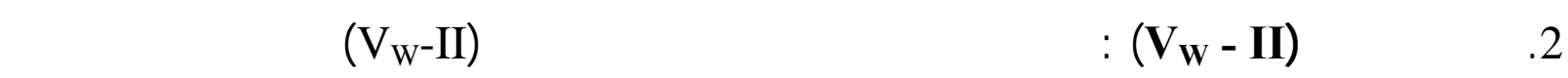

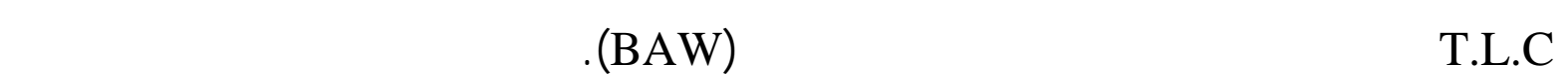

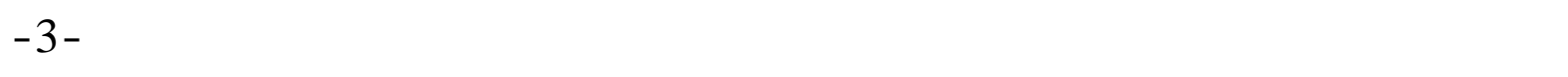

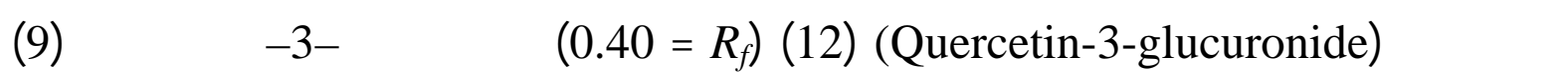

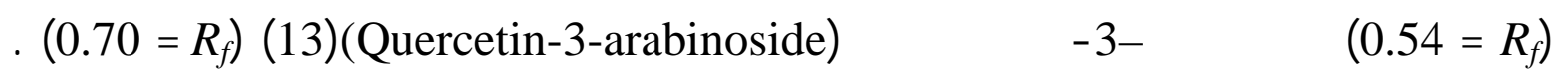
أما الاختبار الثالي فيجرى بعد التحل الحمضي للريلشح (V)

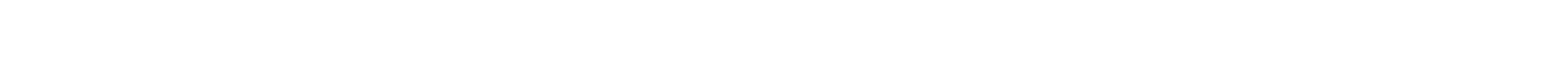

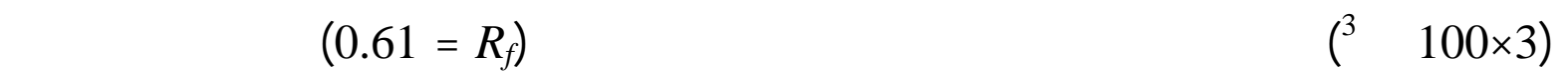

مركب الكورستين (2).

\section{المصادر الهربية}

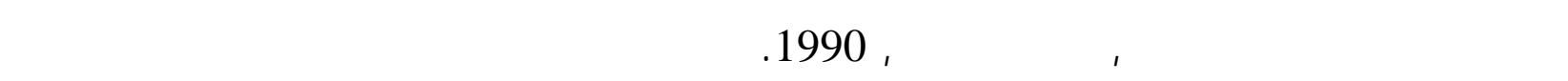
الطباعة والنثر، جلمعة الموصل. العراق. قطب, فوزيطه, 1982. النباتت الطبية، دار المريخ للنشر، الرياض.

\section{المصادر لأجنبية}

Harborne, J. B., 1967.Comparative Biochemistry of the Flavonoids. Academic press, London \& New York. 30 p.

Harborne, J.B., 1973.Phytochemical methods. A Guide to Modern Technique of Plant Analysis, $1^{\text {st }}$. Edn., Printed in Great Britain by Cox \& Wyman Ltd., London. 52$73 \mathrm{p}$.

Mabry, T. J., Markham, K. R., and Thomas, M.B., 1970. The Systematic Identification of Flavonoids. Springer-Verlag, Berlin. 253 p. 